\title{
Development and Validation of the Circumplex Scales of Interpersonal Problems
}

\author{
Michael J. Boudreaux ${ }^{1}$, Daniel J. Ozer ${ }^{2}$, Thomas F. Oltmanns ${ }^{1}, \&$ Aidan G. C. Wright ${ }^{3}$ \\ ${ }^{1}$ Washington University in St. Louis \\ ${ }^{2}$ University of California, Riverside \\ ${ }^{3}$ University of Pittsburgh
}

\section{Author Note}

This work was supported by grants from the National Institute on Aging (RO1-AG045231) and National Institute of Mental Health (L30-MH101760). The views contained are solely those of the authors and do not necessarily reflect those of the funding source.

Portions of the data were presented at the $4^{\text {th }}$ Annual Meeting of the North American Society for the Study of Personality Disorder, New York, NY.

Correspondence concerning this paper should be addressed to Michael J. Boudreaux, Department of Psychology, Washington University in St. Louis, One Brookings Drive, St. Louis, MO 63130. Email: m.boudre@wustl.edu

This article was peer-reviewed and accepted for publication in the journal Psychological Assessment (http://www.apa.org/pubs/journals/pas/). The American Psychological Association holds the copyright for this article. This article has not been copyedited and may not exactly replicate the final version published in the journal. It is not the copy of record. 


\begin{abstract}
The interpersonal circumplex (IPC) is a well-established model of social behavior that spans basic personality and clinical science. Although several measures are available to assess interpersonal functioning (e.g., motives, traits) within an IPC framework, researchers studying interpersonal difficulties have relied primarily on a single measure, the Inventory of Interpersonal Problems Circumplex Scales (IIP-C; Horowitz, Alden, Wiggins, \& Pincus, 2000). Although the IIP-C is a widely used measure, it is currently the only measure specifically designed to assess maladaptive interpersonal behavior using the IPC framework. The purpose of the current study is to describe a new 64-item measure of interpersonal problems, called the Circumplex Scales of Interpersonal Problems (CSIP). Interpersonal problems derived from a pool of 400 personality-related problems were assessed in two large university samples. In the scale development sample $(N=1,197)$, items that best characterized each sector of the IPC were identified, and a set of eight 8-item circumplex scales was developed. Psychometric properties of the resulting measure were then examined in the validation sample $(N=757)$. Results from confirmatory circumplex structural analyses indicated that the CSIP fit well to a quasi-circumplex model. The CSIP converged with the IIP-C and the Revised Interpersonal Adjective Scales (Wiggins, 1995), and associated in theoretically expected ways with broader assessments of adaptive- and maladaptive-range personality traits and symptoms of psychological distress. The CSIP augments the IIP-C with additional content, thereby helping to extend the underlying constructs, and provides an alternative means for studying the interpersonal consequences of personality and psychopathology.
\end{abstract}

Keywords: Interpersonal circumplex, interpersonal problems, inventory of interpersonal problems, personality assessment, psychopathology 


\section{Development and Validation of the Circumplex Scales of Interpersonal Problems}

The interpersonal circumplex (IPC) is a well-established model of social behavior that has helped organize myriad concepts and empirical findings across diverse areas of psychology. Several measures have been developed to assess interpersonal functioning using the IPC structure (for a review, see Locke, 2011), but only one such instrument was explicitly designed to measure interpersonal difficulties, the Inventory of Interpersonal Problems (IIP-C; Horowitz, Alden, Wiggins, \& Pincus, 2000). A virtue of the IIP-C is its link to the IPC, providing both a model and corresponding assessment instrument of maladaptive interpersonal behavior. However, relying on a single measure is not ideal as hypothetical constructs may become reified as scale scores. Multiple measures assessing similar constructs that draw from different traditions and sources of behavioral description would help diversify the range of behaviors the constructs define. They would provide not only alternatives to the IIP-C, but would also serve as independent tests of the theoretical structure of interpersonal problems.

The purpose of the current paper is to describe the development and validation of a new measure of interpersonal problems. The items derive from the Personality Problems Inventory (PPI; Boudreaux, 2016), a general pool of personality-related problems that was developed independently of the IPC and without the goal of constructing an IPC measure in mind. Some initial support for the breadth of the item set was achieved by empirically mapping the items onto all 10 poles of the five-factor model of personality (FFM), from which the PPI, in part, was conceptually derived. The two interpersonal domains of the FFM, Extraversion and Agreeableness, share the same two-dimensional space as the IPC, but differ in the rotation of their

main axes (McCrae \& Costa, 1989; Wiggins \& Broughton, 1991). The two systems also exemplify two different kinds of structural taxonomies. Whereas the FFM is based on simple structure, the 
IPC depicts a circular ordering of variables with graded variation of content mapping the interstitial space between the principal axes. Below, we describe the IPC and how interpersonal problems are represented within a circumplex structure.

\section{The Interpersonal Circumplex}

The IPC is a highly generative model that spans basic personality and clinical psychology. It is defined by two orthogonal, bipolar dimensions of Dominance (dominance vs. submissiveness) and Affiliation (coldness vs. warmth). The structural model that has been applied to the IPC posits that interpersonal variables (e.g., sociable, hostile) are arranged in a circular array, jointly defined by the two underlying dimensions. The IPC is typically divided into octants, but can be divided differently depending on how narrow or broad one wishes to conceptualize the interpersonal space. The theoretical ordering of variables around the IPC provides a nomological net (Gurtman, 1992a) within which any number of interpersonal variables can be identified. When applied to interpersonal problems, each octant reflects a maladaptive, interpersonal pattern. Figure 1 presents a graphical display of interpersonal problems projected onto the IPC, including code letters used to identify each octant as well as their angular locations.

A perfect circumplex is defined by three properties, listed in order of increasing specificity (Gurtman, 1994). First, differences among variables are reducible to differences along two fundamental dimensions (e.g., Dominance and Affiliation). Second, each variable has an equal projection onto the circumference of the circle, as represented by the variable's distance from the origin (i.e., each variable has the same communality, or same degree of shared variance with the two underlying dimensions). Third, the distribution of variables around the circle is uniform, with no major gaps or regions of more or less density (i.e., the variables are equally spaced around the circle). As Gurtman (1994) noted (see also Gurtman \& Pincus, 2003), this last criterion 
differentiates circumplex models of personality from simple structure models, such as the Big Five (e.g., Goldberg, 1992). In contrast to circumplex structure, simple structure minimizes the spread of trait variance over factors, and thus models clusters of variables with high concentration on one (and only one) dimension.

Thus, the circular model on which the IPC is based is a theoretical ideal, geometric representation of the interrelationships among a set of variables. The expected correlation structure is characterized by a circular, repeating pattern of decreasing values followed by increases in a wave-like pattern. For an ideal circle, each row in the correlation matrix is the same as the previous row, but moved one space to the right, with identical values along the diagonal (Guttman, 1954). A number of procedures have been developed to determine how well putatively circumplex measures conform to the expected circular pattern (e.g., Browne, 1992; Fabrigar, Visser, \& Browne, 1997; Rounds, Tracey, \& Hubert, 1992; Wiggins, Steiger, \& Gaelick, 1981), with several measures producing varying results (e.g., Acton \& Revelle, 2002; Gaines et al., 1997; Gurtman \& Pincus, 2000). One notable difference is the presence or absence of a general factor, corresponding to the average correlation among all variables. In some instances (as in the case of the IIP-C) the general factor can be attributed to a meaningful construct (e.g., psychological distress). In other cases it is not clear whether the general factor is capturing distress, rigidity, an idiosyncratic response style, or some other unknown quality.

\section{Interpersonal Problems and the IIP - Circumplex Scales}

Beginning in the late 1970s, Horowitz initiated an influential program of research on the theory and measurement of interpersonal problems. While theorists have long emphasized the role of social relationships in personality and personality pathology (e.g., Horney, 1945; Leary, 1957; Sullivan, 1953), until Horowitz and colleagues (e.g., Horowitz, 1979; Horowitz, Rosenberg, Baer, 
Ureño, \& Villaseñor, 1988; Horowitz \& Vitkus, 1986; Horowitz, Weckler, \& Doren, 1983), little work had systematized interpersonal problems in a way that could be useful to researchers and practitioners alike. Building on the work of a psychoanalytic case study (Horowitz, Sampson, Siegelman, Weiss, \& Goodfriend, 1978), Horowitz (1979) identified a pool of 127 problems by examining the complaints of 28 patients seeking psychotherapy. Scaling methods were applied to these items, which ultimately led to initial construction of the IIP (Horowitz et al., 1988). Horowitz et al. developed six subscales corresponding to behavioral inhibitions (i.e., things people find "hard to do") and behavioral excesses (i.e., things people "do too much").

When a principal components analysis (PCA) was performed on the six subscales, two bipolar components emerged, corresponding to the dimensions of the IPC: coldness versus warmth and submissiveness versus dominance. These findings prompted Alden, Wiggins, and Pincus (1990) to develop circumplex scales for the IIP (i.e., IIP-C). They first statistically removed a general distress factor found to underlie scores on the IIP, and then submitted the inter-item correlations to a PCA and extracted the first two components. A set of eight 8-item scales was developed and cross-validated in an independent sample. When the eight scales were correlated and factored, the loadings on the first two principal components showed a clear circumplex structure. Each vector from the origin represents a "blend" of the two underlying dimensions, depending on the scale's location on the circle.

The IIP-C therefore provides a measure dedicated to the assessment of maladaptive variants of the IPC theoretical model, and has since been widely used. A search on the PsycINFO database for the "Inventory of Interpersonal Problems" resulted in over 1,000 hits since Alden et al. first reported its development. The literature has clearly demonstrated the value of the IIP-C to address a number of research and applied issues. For example, it has proven a useful tool for 
conceptualizing psychopathology (e.g., Pincus \& Wright, 2011; Przeworski et al., 2011), evaluating psychotherapeutic processes and outcomes (e.g., Horowitz, Rosenberg, \& Bartholomew, 1993; Vittengl, Clark, \& Jarrett, 2003), and understanding adolescent and young adult attachment styles (e.g., Bartholomew \& Horowitz, 1991; Brown \& Wright, 2003). However, while the IIP-C is a popular measure, it is currently the only representation of the interpersonal problems domain. One potentially problematic consequence of relying on a single measure is that the underlying constructs may become synonymous with specific scales, and thus narrow the theoretical scope of interpersonal problems. Potential additional limitations may be due to the fact that the IIP-C is a proprietary instrument, with an associated charge per administration. In many research and applied settings, even a modest fee may be prohibitive. A need therefore exists for equally strong and freely available measures of interpersonal problems that may complement, or provide an alternative to, the IIP-C.

Other areas of personality assessment have benefited from multiple measures developed to assess the same constructs. Most notably, numerous measures have been designed to assess the Big Five/FFM traits (for a review, see De Raad \& Perugini 2002). For example, the popular (but proprietary) Revised NEO Personality Inventory (Costa \& McCrae, 1992) has been recreated using the International Personality Item Pool (Goldberg et al., 2006) in long form (Goldberg, 1999) and as two separate short forms (Johnson, 2014; Maples, Guan, Cater, \& Miller, 2014). Additional faceted inventories of the Big Five/FFM have also been created (e.g., Hofstee, De Raad, \& Goldberg, 1992; Soto \& John, 2016), as well as very brief variants (e.g., Gosling, Rentfrow, \& Swann, 2003; Rammstedt \& John, 2007). In the domain of maladaptive personality, a number of measures have been created to assess similar traits (e.g., Clark, 1993; Harkness \& McNulty, 1994; Livesley \& Jackson, 2009; Krueger et al, 2012) often using scales with the same name, although 
specific content clearly differs across scales. One benefit of having multiple related, but nonisomorphic measures is that they provide better coverage of the full conceptual space, and allow for better empirical identification of the structure and correlates of personality.

To illustrate the importance of diverse measures, consider the case of popular depression questionnaires, which vary in terms of content and structure, as determined by numerous factor analyses (see Shafer, 2006, for a review). As Shafer noted, several studies have shown that patterns of correlations, group differences, and recorded treatment response can all vary as a function of the specific make-up of the depression measure in use. Similarly, alternative articulations of the specific scales that comprise the interpersonal problems space may yield different perspectives on the interpersonal nature of external variables (e.g., Zimmermann \& Wright, 2017), the interpersonal styles of patient groups (e.g., Przeworkski et al., 2011; Wright et al., 2013), and treatment effectiveness (e.g., Bateman \& Fonagy, 1999). In each of these cases, the availability of multiple measures may yield greater confidence in the generalizability of findings when they agree across measures, and greater specificity of empirical results and refinement of theory when the measures disagree.

\section{Personality Problems Inventory: Review of Item Development}

As noted above, the PPI is a broad and reasonably comprehensive list of personality-related problems. Procedures for item development are detailed in Boudreaux (2016), and are only briefly summarized here. An initial item pool covering social, emotional, and motivational domains of functioning was first generated by examining individuals' open-ended self-reports of problems (Boudreaux, Piedmont, Sherman, \& Ozer, 2013) and later extended by consulting two comprehensive measures of personality and problems: the NEO Problems in Living Checklist (NEO-PLC; McCrae \& Costa, 2010) and the California Adult Q-Set (CAQ; Block, 1961, 2008). 
Participants in the Boudreaux et al. study $(N=152)$ each listed at least one social, emotional, or motivational problem. Each response was content analyzed and simplified using short verb phrases. As an example of a social problem, one person wrote:

I am somewhat shy, which interferes with meeting or getting close to people. However, I feel that I am also scared of putting myself out there for fear of rejection and that interferes greatly with my relationships. When I do get comfortable with someone, I find that I am always wondering what they think of me and that causes me to pull back and be shy again. Sometimes I will not go somewhere or do something because of the above reasons.

From this response, the items "acting shy around others," "difficulty making friends," "feeling uncomfortable with being close or intimate with others," "being too concerned about what other people think," "pushing away other people who get too close," and "avoiding people or social situations" were written.

Items derived from individuals' self-reports were then classified by conceptually similar items contained within the NEO-PLC and CAQ, and new items were written to cover any gaps. Examples of interpersonal problems include: "bossing around other people too much" written for the NEO-PLC item "domineering, pushy, bossy, dictatorial, or authoritarian style," and "difficulty developing close and lasting relationships" written for the conceptual opposite of the CAQ item "has warmth; has the capacity for close relationships; compassionate." As a result, a pool of 310 problems was initially developed and reported in the Boudreaux (2016) study; additional items were subsequently written by revisiting each source (i.e., the open-ended responses, NEO-PLC, and $\mathrm{CAQ}$ ) and reviewing the relevant literature, bringing the total number of items to 400 .

\section{Overview of the Present Study}


The goal of the current study was to develop a measure of maladaptive interpersonal behavior using items derived from the PPI. Consistent with interpersonal theory, we aimed to develop circumplex scales to measure the octants of the IPC. We performed circumplex analyses on a subset of interpersonal problems assessed in two large university samples. Items that best characterized each sector of the IPC were identified, and a set of eight 8-item scales was developed. Psychometric properties of the resulting measure were then examined in a second university sample. We assessed its patterns of relations and structural convergence with the IIP-C and the Revised Interpersonal Adjective Scales (IAS-R; Wiggins, 1995). We expected that the new interpersonal problems scales would assess similar constructs as, and share a comparable structure to, the IIP-C. To the extent that interpersonal problems and interpersonal dispositions are similarly organized, we expected the two domains to overlap, but based on previous research (e.g., Gurtman, 1992b; Hopwood, Koonce, \& Morey, 2009), did not expect them to be isomorphic. We evaluated the construct validity of the new circumplex scales with broader assessments of adaptive- and maladaptive-range personality traits. Finally, we examined the incremental validity of the new measure and the IIP-C in accounting for variance in personality traits and symptoms of psychological distress.

\section{Method}

\section{Samples and Procedures}

Data were drawn from two independent college student samples. The first sample (the "scale development" sample) consisted of 1,197 undergraduate students (771 women, 423 men, 3 did not indicate their gender) enrolled at a public university in Southern California. Average age was 19.4 years $(S D=1.8$; range $=18$ to 42$) ; 41.2 \%$ were Asian or Pacific Islander, $32.9 \%$ were Hispanic, 10.4\% were White, 3.8\% were African American, 5.4\% were Middle Eastern or Indian, 
and $6.2 \%$ were mixed, other, or had missing data. One hundred seventy-two participants (14.4\%) reported having received counseling at least once in their lifetime; average time in counseling was approximately 10 months $(S D=18.3$; range $=1$ week to 13 years $)$. Thirty-nine participants $(3.3 \%)$ reported being diagnosed with a mental disorder (e.g., depression, bipolar disorder, post-traumatic stress disorder).

The second sample (the "validation" sample) consisted of 757 undergraduate students enrolled at a public university in western Pennsylvania. Due to a project administration error, gender was recorded for only 200 participants ( 123 women, 77 men). Average age was 18.7 years $(S D=1.7 ;$ range $=18$ to 49$) ; 74.9 \%$ were White, $14.1 \%$ were Asian or Pacific Islander, $4.6 \%$ were African American, 2.9\% were Hispanic, and 3.4\% were mixed, other, or had missing data. One hundred seventy participants (22.5\%) reported to be receiving counseling at the time of the study or have received counseling at least once in the past; average time in counseling was approximately 18 months $(S D=24.8$; range $=1$ week to 11 years $)$. Eighty-four participants $(11.1 \%)$ reported being diagnosed with a mental disorder (e.g., anxiety, depression, attention-deficit disorder).

Data for the scale development sample were collected in multiple studies over a one-year period. Participants in this sample completed the PPI, among other measures not reported here. Data for the validation sample were collected over two semesters on all measures described below. Questionnaires were administered over the Internet using online survey software for both samples. All participants participated on personal computers at home or school, and received course credit for their participation. Institutional review board approval was obtained for data collection.

\section{Measures}

Personality Problems Inventory (PPI). As noted above, an initial study (Boudreaux, 2016) reported the development of 310 specific social, emotional, and motivational problems. This 
pool was later extended by adding 90 additional problems. For the purpose of the current study, four independent judges coded whether each of the 400 problems is interpersonal (i.e., involving at least one other person or the presence of another person is implied). Three or more judges agreed on 156 problems. Of these, 18 items that were vague or redundant with another item were removed. The remaining subset of 138 interpersonal problems was analyzed. Participants were asked to indicate how much they experience each problem on a scale from 0 to $3(0=$ Not a Problem, $1=$ Minor Problem, 2 = Moderate Problem, $3=$ Serious Problem). Participants in the scale development sample responded to all 400 items; participants in the validation sample responded to the subset of 138 items.

Inventory of Interpersonal Problems (IIP-C). The IIP-C (Horowitz, Alden, Wiggins, \& Pincus, 2000) is a 64-item self-report instrument designed to assess interpersonal difficulties. The items are divided in two sections that describe behaviors that people find "hard to do" and "do too much." Participants are asked to rate how distressing each problem is on a 5-point, Likert-type scale ranging from 0 (Not at all) to 4 (Extremely). Research has supported the reliability and validity of the octant scales in both community and college student samples (Alden, Wiggins, \& Pincus, 1990; Horowitz et al., 2000). Alpha reliabilities in the current study ranged from .78 (Domineering/Controlling) to .89 (Socially Inhibited and Nonassertive) $(M d n .=.83)$.

Interpersonal Adjective Scales - Revised (IAS-R). The IAS-R (Wiggins, 1995) consists of 64 adjectives designed to assess the eight octants of the IPC. The items derive from Goldberg's (e.g., 1982) extensive list of 1,710 trait descriptive terms. Each adjective is rated on an 8-point, Likert-type scale ranging from 1 (extremely inaccurate) to 8 (extremely accurate). The IAS-R octant scales possess strong psychometric and circumplex properties and converge with numerous other self-report personality measures (Wiggins \& Broughton, 1991; Wiggins, Trapnell, \& 
Phillips, 1988). To clarify the meaning of unfamiliar or difficult words (e.g., "boastless," "ironhearted," "unwily"), we included definitions of each adjective. Alpha reliabilities in the current study ranged from .74 (Unassuming-Ingenuous) to .92 (Cold-Hearted and GregariousExtraverted $)(M d n .=.90)$.

Big Five Inventory - 2 (BFI-2). The BFI-2 (Soto \& John, 2016) is a 60-item, faceted version of the BFI (John, Donahue, \& Kentle, 1991). Each domain consists of three 4-item facet scales. The items are in the form of short phrases based on prototypical markers of the Big Five trait dimensions. Respondents indicate the extent to which they agree or disagree with each statement on a 5-point, Likert-type scale ranging from 1 (disagree strongly) to 5 (agree strongly). The domain and facet scales have been shown to be highly reliable, stable over time, and to possess convergent and discriminant validity with respect to other Big Five instruments (Soto \& John, 2016). In the current study, alpha reliabilities for the domain scales ranged from .81 (Agreeableness and Openness) to .89 (Neuroticism) $(M d n .=.83)$; for the facet scales, alphas ranged from .57 (Responsibility) to .86 (Social Engagement) $(M d n .=.73)$.

Personality Inventory for DSM-5 - Faceted Short Form (PID-5-FSF). The PID-5-FSF is a 100-item version of the PID-5 (Krueger, Derringer, Markon, Watson, \& Skodol, 2012) designed to index the five domains of the DSM-5 personality trait model. Each domain of the PID5-FSF consists of three 4-item facet scales. Item responses are based on a Likert-type scale ranging from 0 (Very False or Often False) to 3 (Very True or Often True). The reliability and validity of the PID-5 has been supported in community, treatment-seeking, and college student samples (Krueger et al., 2012; Wright et al., 2012). In the current study, alpha reliabilities for the domain scales ranged from .81 (Detachment) to .89 (Antagonism) $(M d n .=.85)$; for the facet scales, alphas ranged from .53 (Withdrawal) to .86 (Impulsivity and Distractibility) $(M d n .=.81)$. 
Brief Symptom Inventory (BSI-18). The BSI-18 (Derogatis, 2000) is a short, self-report screening inventory designed to assess psychological distress. The BSI-18 has been shown to correlate strongly with both the Symptom Checklist-90-Revised and the 53-item version of the BSI (Derogatis, 2000). Participants in the current study were asked to respond to each item in terms of how they have been feeling during the "past 7 days." The following alpha reliabilities were obtained: depression (.85), anxiety (.81), and somatization (.75).

Validity Scales. Validity scales were used in both samples to identify inconsistent or careless responders. In the scale development sample, 10 duplicate items were included from the PPI. In the validation sample, 10 items describing behaviors that are very common (e.g., "I like listening to music from time to time") or very uncommon (e.g., "I've won the Dag Hammarskjöld prize") were included. Percent of maximum possible (POMP; Cohen, Cohen, Aiken, \& West, 1999) scores were computed in each sample by dividing the summed responses across all 10 items by 30 (i.e., the maximum possible score on a 4-point scale) (items describing very common behaviors were reverse coded). Cases with a POMP score greater than .33 were excluded from all analyses. Twenty-eight of 1,197 cases (2.34\%) were removed from the scale development sample, and 39 of 757 cases $(5.15 \%)$ were removed from the validation sample.

\section{Overview of Data Analytic Methods}

Data analyses took place in two phases. The goal of the first phase was to identify a subset of items that best represent the IPC from the list of 138 interpersonal problems. Circumplex analyses were performed in iterations on two random halves $(n=585, n=584)$ of the scale development sample, and then on the full sample to further reduce the number of items of the final scale to 64 (8 items per octant scale). The primary steps in the circumplex analyses of item scores are summarized as follows: 
1. Scores were first transformed using an ipsatized scoring procedure where each score was expressed in standard deviation units from the participant's mean score across all items.

2. The correlations among the ipsatized item scores were subjected to a PCA. The first two principal components were extracted and a varimax rotation was applied to the component loading matrix.

3. The loadings on the two orthogonal components were plotted in two-dimensional space, and the angle of each item (with respect to the $X$ axis) was computed by treating the component loadings as coordinate values: $\theta=\arctan (Y / X)$

4. Item communalities $\left(h^{2}\right)$ were obtained by taking the sum of the squared loadings for each variable on the two principal components.

To formally test whether the final 64-item scale, hereafter referred to as the Circumplex Scales of Interpersonal Problems (CSIP), conforms to a circumplex or quasi-circumplex pattern, we subjected the pattern of correlations in the scale development and validation samples to confirmatory circumplex structural analysis as described by Browne (1992). Browne's method is a confirmatory approach to examining the circumplexity of a set of scales based on covariance structural modeling (see Fabrigar, Visser, \& Browne, 1997, for a non-technical introduction to these methods). In brief, these methods test whether the observed correlation matrix matches an implied correlation matrix based on a circular correlation function. Models can be evaluated using standard covariance structural fit indices. All models were implemented in R using Grassi, Luccio, and Di Blas' (2010) package, CircE. Four sets of models were evaluated for each sample.

The goal of the second phase was to evaluate the reliability and validity of the CSIP. These analyses were conducted using the validation sample. Basic descriptive statistics and inter-scale correlations are presented. Structural similarity was evaluated at the item- and scale-levels across 
the scale development and validation samples by computing Tucker-Burt-Wrigley-Neuhaus coefficients of congruence (see Guadagnoli \& Velicer, 1991). These coefficients were computed following a rotation of the loading matrices to maximum similarity. Structural convergence was assessed with respect to both the IIP-C and IAS-R circumplex scales. Additional evidence of construct validity was examined by relating the CSIP to broader assessments of personality, including the BFI-2 and PID-5-FSF. Evidence of incremental validity was examined by predicting personality traits (on the BFI-2 and PID-5-FSF) and symptoms of psychological distress (on the BSI-18) from the CSIP and IIP-C octant scales.

\section{Results}

\section{Scale Development}

Within each of the two subsamples of the scale development sample, the correlations among the 138 ipsatized item scores were submitted to a PCA and two components were extracted. The item loadings on the two orthogonally rotated components were plotted on a two-dimensional plane and the angle of each item was computed with reference to the $X$ and $Y$ coordinate values. Items with low communality estimates $(<.10)$ in both subsamples were then considered for deletion. Because the component loadings are interdependent (e.g., item deletions may alter the loading of other items within the total set), the four data analytic steps outlined above were repeated after items were successively removed. A preliminary set of 12-item octant scales were constructed by (a) dividing the two-dimensional plane into eight equal sectors (with theoretical midpoints of $90^{\circ}, 135^{\circ}, 180^{\circ}, 225^{\circ}, 270^{\circ}, 315^{\circ}, 360^{\circ}$, and $45^{\circ}$ ) and (b) examining each item's communality estimate and angular location with respect to theoretical values. Attempts were made to balance the octant's range (i.e., the angular displacements of items falling within each sector) and communalities to ensure full coverage of the octant's construct. In some cases, rational 
decisions were made for item placements that fell between two sectors. Congruence coefficients across the two random subsamples on the reduced set of 96 items indicated fair to strong similarity $($ Factor $1=.97$, Factor $2=.92)$.

To further refine the scales for a more efficient assessment of interpersonal problems, the subset of 96 items was reexamined in the total scale development sample of 1,169 participants. The four data analytic steps were repeated after sequentially removing items until arriving at a final set of 8-item octant scales. Item communalities, item-total scale correlations, and angular locations were used to select the best items. For example, the item "having trouble asserting myself" was selected for the Nonassertive scale because it had a higher communality, item-total scale correlation, and was nearer to the theoretical midpoint than other items within this region, such as the item "difficulty assigning tasks and responsibilities to others," which was discarded. The average span of items falling within each octant was $42^{\circ}$ in the scale development sample and $38^{\circ}$ in the validation sample. The CSIP items and scoring procedures are provided in the supplemental materials. They may also be obtained by contacting the authors.

\section{Validation of the CSIP}

Descriptive Statistics and Circumplex Properties of the CSIP. Table 1 presents descriptive statistics, both overall and separately for each gender, for the CSIP raw octant scales as well as for the total score across all scales in the validation sample. As shown, participants had an average total score of 44.7 ( $S D=25.6$; range is 0 to 152 , of 192 possible), or $23 \%$ of the maximum possible. The highest ratings corresponded to the Socially Inhibited (FG) scale, and the lowest to the Domineering (PA) scale. Independent sample $t$-tests indicated significant gender effects for four of the eight scales. Men reported more severe Domineering (PA) problems, whereas women reported more severe Nonassertive (HI), Exploitable (JK), and Self-Sacrificing 
(LM) problems. Alphas ranged from .79 (Intrusive [NO]) to .89 (Socially Inhibited [FG]) $(M d n .=$ $.85)$. No ethnicity differences were found. Congruence coefficients computed on the underlying dimensions of Dominance and Affiliation for the scale development and validation samples demonstrated strong similarity at both the item- $($ Factor $1=.97$, Factor $2=.97)$ and scale-levels $($ Factor $1=1.00$, Factor $2=1.00)$.

The correlations among the eight scales (both summed and ipsatized) are presented in Table 2. As shown in the upper portion of the table, correlations among the raw scores ranged from .13 to .78. This pattern of positive intercorrelations is consistent with previous research, indicating the presence of a general severity factor underlying endorsements of distress (Alden et al., 1990; Horowitz et al., 1988). Despite the uniformly positive correlations due to the general factor, the correlation pattern is characterized by a circular, repeating pattern of values in each row and column. Ipsatized scores control for the general factor by expressing each score as a deviation from the participant's mean score across all items. As shown in the lower portion of the table, values among the ipsatized scores ranged from -.59 to .47 . This pattern of correlations also conforms well to expectations about circular structure: Scales adjacent to one another shared the highest positive correlations, scales opposite one another shared the highest negative correlations, and scales at $90^{\circ}$ angles shared the lowest correlations. When the correlations among the ipsatized scale scores were submitted to a principal components analysis, a clear two-component solution emerged (eigenvalues $=2.79,2.24$, and 0.85 ) which accounted for $62.89 \%$ of the variance.

To examine the circumplex structure of the CSIP, we tested three models for fit to the observed correlation matrix in the scale development and validation samples. The first model is a highly restrictive model that assumed equal communalities and angular distances between scales. The second and third models relaxed the equality constraint on the communalities and angular 
distances, respectively. Models two and three are tests of a quasi-circumplex structure. Results are summarized in Table 3. As shown, the best fitting model in both samples is a quasi-circumplex with unequal spacing and equal communalities. However, all models achieved good or excellent fit by the CFI and NNFI, and adequate fit or better as judged by the RMSEA. Note that these results compare favorably to the well-established IIP-C and IAS-R models estimated in the validation sample (see Supplemental Table 1).

Convergence of the CSIP with the IIP-C. Table 4 presents validity coefficients of the CSIP and IIP-C using an ipsatized scoring procedure for both instruments. Correlations on the diagonal of the table represent convergent validity coefficients between the CSIP scales and their IIP-C counterparts. Convergent coefficients ranged from .58 to $.73(M d n .=.66)$. In every instance, each convergent correlation was the highest in each respective row and column. Discriminant validity coefficients (on the off-diagonal) ranged from -.50 to $.48(M d n .=-.10)$. Among the nonipsatized scores (not shown), convergent coefficients were somewhat higher $(M d n .=.77)$, but discriminant coefficients were considerably higher $(M d n .=.33)$, as was expected due to the general factor mentioned above.

The correlations among the 16 ipsatized scale scores from the CSIP and IIP-C were then subjected to a joint PCA, and rotated for maximum convergence to theoretical locations. A clear two-component structure emerged (eigenvalues $=5.19,3.94,1.22$ ), which accounted for $57.05 \%$ of the variance. A visual representation of the structural convergence of both inventories is provided in Figure 2, and the component loadings, communality estimates, and angular locations of scale pairs are presented in Table 5. The component loadings clearly indicate that the CSIP and IIP-C share a common circumplex structure. Corresponding scales from the two instruments were located fairly close to each other. The only exception was for Distant (DE), with an angular 
discrepancy of $17.5^{\circ}$. On average, scale pairs differed from each other by $6.6^{\circ}$; the CSIP differed from theoretical locations by $3.9^{\circ}$, whereas the IIP-C differed by $8.6^{\circ}$.

Convergence of the CSIP with the IAS-R. Correlations between interpersonal problems and interpersonal dispositions are presented in Table 6 (scores from the CSIP were ipsatized). Convergent coefficients between the CSIP and IAS-R scales ranged from .12 to $.57(M d n .=.41)$, and discriminant coefficients ranged from -.63 to $.51(M d n .=-.09)$. Although the convergent correlations were generally weaker than those observed in Table 4, the IAS-R is a measure of interpersonal traits and the CSIP is a measure of interpersonal problems. The IIP-C demonstrated a very similar pattern of results: convergent coefficients ranged from .19 to $.55(M d n .=.41)$, and discriminant coefficients ranged from -.51 to $.55(M d n=-.07)$. A comparison of results between the CSIP and IIP-C with the IAS-R is provided in Supplemental Table 2.

Because the location of a variable within the IPC determines its predicted patterns of relations with other measures, empirically evaluating the congruence between alternative IPC measures is essential. In order to identify the locations of the problems scales within the IPC, dimensional scores for Dominance and Affiliation using the IAS-R were computed by weighting each scale by either the sine $(Y)$ or cosine $(X)$ of that scale's angular location on the circle, and then taking their sums (for geometric formulas, see Wiggins, 1995). These scores were correlated with each CSIP and IIP-C octant scale, and converted to polar coordinates (vector length and angular location) using standard trigonometric procedures (e.g., Gurtman, 1994; Wiggins, Phillips, \& Trapnell, 1989). Average vector length of the CSIP scales when projected onto the IAS-R was .52 (range $=.36$ to .61$)$ and the average vector length of the IIP-C scales when projected onto the IAS-R was .51 (range $=.36$ to .65$)$. On average, the CSIP octant scales differed with their respective IAS-R counterparts by $25.0^{\circ}$, and the IIP-C octant scales differed by $20.0^{\circ}$. 


\section{Associations of the CSIP and IIP-C with adaptive- and maladaptive-range personality}

traits. To the extent that a given personality construct is interpersonal in nature, a particular pattern of correlations with the octant scales of the CSIP and IIP-C is expected to emerge. When plotted on a line, this expected pattern of associations gives rise to a cosine curve that can be summarized by three structural parameters: elevation, amplitude, and angular displacement. Derivation of these parameters has been termed the structural summary method (SSM) and is detailed in other reports (e.g., Gurtman \& Pincus, 2003; Wright, Pincus, Conroy, \& Hilsenroth, 2009). Elevation represents the average correlation of a target construct with the octant scales of the IPC; in the case of the CSIP and IIP-C, elevation signals the degree to which a construct is associated with non-specific interpersonal distress. Amplitude represents the degree to which the construct correlates differentially with the octants of the IPC. Amplitude is the distance between the mean level of the curve (i.e., elevation) and its peak, indicating the extent to which a construct is associated with specific interpersonal content. Angular displacement represents the angle corresponding to the peak of the curve, thus specifying a construct's location on the IPC. The displacement of a construct is only interpretable for prototypical profiles. To represent how prototypical a profile is, we report $R^{2}$ values to index the goodness-of-fit between the observed and predicted cosine curve. $R^{2}$ values equal to or greater than .70 are considered acceptable, and values equal to or greater than .80 are considered good. Finally, we report confidence intervals for the SSM parameters using a recently developed resampling-based approach (Zimmerman \& Wright, 2017).

We projected the BFI-2 scales onto the CSIP and IIP-C problems circumplexes, separately. Structural parameters are reported in Table 7. At the domain level, the interpersonal problem profiles for Extraversion, Agreeableness, and Neuroticism conformed well to the expected circumplex pattern, and each had elevations greater than $|.20|$ indicating that these trait domains 
were associated with general interpersonal distress. As expected, the trait domains and facets of Extraversion and Agreeableness demonstrated specificity in their associations with interpersonal problems (i.e., amplitudes $>.15$ ). Angular displacements of the Extraversion facet scales ranged from $38.1^{\circ}$ to $82.1^{\circ}$ and those for Agreeableness ranged from $291.6^{\circ}$ to $323.6^{\circ}$, placing them in the Warm-Dominant and Warm-Submissive quadrants of the IPC, respectively. A very similar pattern of results was observed for the IIP-C.

The interpersonal problem profiles for the PID-5-FSF trait domains also conformed well to the expected circumplex pattern, except Disinhibition, and all domain scales had elevations greater than .20 (see Table 8). The two interpersonal domains of the PID-5-FSF, Detachment and Antagonism, had amplitudes greater than .20, indicating a differential interpersonal pattern. All three Detachment facets and two of the Antagonism facets (Manipulativeness and Grandiosity) had amplitudes greater than or equal to a heuristic cutoff of .15. Angular displacements of the Detachment facet scales ranged from $181.9^{\circ}$ to $202.4^{\circ}$ and those for Antagonism ranged from $98.1^{\circ}$ to $110.9^{\circ}$, placing them in the Cold-Submissive and Cold-Dominant quadrants of the IPC, respectively. Once again, a very similar pattern emerged for the IIP-C. These results are also highly consistent with a previous study that examined the structural parameters of the PID-5 when projected onto the IIP-C problems circumplex (Wright et al., 2012). For the interested reader, correlations of the CSIP and IIP-C with the BFI-2 and PID-5-FSF are presented in Supplemental Tables 3 and 4 .

Incremental Validity of the CSIP and IIP-C. To examine the incremental validity of the CSIP and IIP-C, two sets of hierarchical multiple regression analyses were conducted. In the first model, each of the BFI-2, PID-5-FSF, and BSI-18 scales were regressed on the IIP-C octant scales at Step 1. The CSIP was entered at Step 2, along with the IIP-C. The second model examined the 
incremental validity of the IIP-C by reversing Steps 1 and 2. The explained variance for each outcome is presented in Table 9. The first column indicates the total percentage of variance explained by both measures. For example, the CSIP and IIP-C together explained nearly $60 \%$ of the variance in Extraversion. The second and third columns separate the percentage of variance uniquely associated with the CSIP and IIP-C, and the final column shows the percentage of shared variance. In most cases, the CSIP and IIP-C shared overlapping variance in their prediction of each outcome. However, both measures also explained unique variance, after accounting for the other measure. These results indicate that the CSIP increments the prediction of the BFI-2, PID-5-FSF, and BSI-18 scales above and beyond the IIP-C. While the same is also true of the IIP-C, these findings suggest that the CSIP and IIP-C are not entirely overlapping, but that each adds substantive content to the assessment of interpersonal problems.

\section{Discussion}

The purpose of the present study was to provide initial reliability and validity data for a novel circumplex measure of interpersonal problems. Although several measures are available to assess interpersonal constructs within an IPC framework, researchers studying interpersonal difficulties have relied primarily on a single measure, the IIP-C. Several studies have demonstrated the reliability and validity of the IIP-C, as well as its value in many research and applied settings. However, we believe that the field could benefit by having multiple, freely available measures to assess similar interpersonal constructs. As we noted earlier, other areas of personality assessment have profited from multiple instruments, most notably those designed to assess the Big Five/FFM. The International Personality Item Pool collaborative (Goldberg et al., 2006), for example, has had a major impact on the field, and is based on the compelling argument that robust measures should be freely available to the scientific community. Moreover, we noted that in other areas of clinical 
assessment, differences in item content across measures has led to increased understanding of specific aspects of constructs that drive associations with external measures, lead to group differences in scores, and ultimately respond to treatment interventions. Finally, there is a trend toward open science, which we believe should include methodology (e.g., to be able to replicate findings, researchers should have access to the same free materials when possible), as well as a growing recognition of a need for larger samples. However, as sample sizes increase, so do the financial costs associated with administering commercial instruments.

In addition to the advantages of having freely available instruments, multiple measures can help reduce the equivocality of any single measure, and thereby avoid a situation in which hypothetical constructs might become synonymous with scale scores. If the behavioral referents of the constructs assessed by any given measure were exhaustively defined and systematically sampled, then one would not need (or even expect to find) alternative measures. However, in the case of the IIP-C, the domain of interpersonal problems was not exhaustively defined, but was based on the complaints of a relatively small sample of 28 patients seeking psychotherapy. It seems reasonable to suggest that independent studies of other populations using alternative methods might identify additional content. The PPI, through which the CSIP was constructed, was developed by content analyzing young adults' open-ended self-reports of problems and two comprehensive measures of personality. Given the different approaches taken by the CSIP and IIP-C, convergence between the two measures would strongly substantiate the generalizability of the underlying constructs. The two approaches are also alike, however, in that neither instrument was designed explicitly to measure the constructs of the IPC. Rather, they were guided by an effort to maximize ecological validity via a "bottom-up" approach to identify problems that people experience in their lives. 
The results demonstrated that interpersonal problems derived from the PPI were associated with each octant of the IPC. The octant scales constructed to summarize the circle were shown to possess acceptable psychometric properties. Internal consistency estimates were within satisfactory ranges, no ceiling or floor effects were present, and the scales were structurally stable across two independent samples. Results from confirmatory analyses indicated that the CSIP conformed well to a quasi-circumplex model with unequal spacing and equal communalities. However, the CSIP performed as well if not slightly better than the IIP-C in all three models tested. Inspection of Figure 2 and Table 5 reveals that most CSIP octant scales have slightly better angular locations than their IIP-C counterparts. The greatest differences can be seen within the HostileDominant quadrant. These findings are not inconsistent with data based on the IIP-C standardization sample, which shows, for example, that Distant (DE) is rotated by $27^{\circ}$ from its theoretical location (Horowitz et al., 2000, see figure 5.1, p. 34).

Despite small differences in rotation and model fit, the CSIP demonstrated very good convergent and discriminant validity with the IIP-C. Convergent validity coefficients ranged from .58 (Self-Centered) to .73 (Socially Inhibited) and each convergent correlation was stronger than correlations between non-corresponding scale pairs. Five scales had the highest negative correlation with an opposing scale, with three exceptions: CSIP Distant (DE), Exploitable (JK), and Self-Sacrificing (LM) were more strongly correlated to an opposing neighboring IIP-C scale than with a theoretical opposite. The size of these differences was quite small, however, with differences of .04 or less. The CSIP and IIP-C also shared very similar patterns of relations with external variables, including adaptive- and maladaptive-range personality traits and symptoms of psychological distress. Overall, these data support the validity of the CSIP. As indicated in Figure 2 and Table 5, the CSIP and IIP-C clearly share a similar circumplex space. 
Convergent and discriminant validity with the IAS-R was also good, with some notable exceptions. CSIP Self-Centered (BC), Distant (DE), and Exploitable (JK) had higher correlations with neighboring IAS-R scales than with their theoretically appropriate counterparts. However, this was also true of the IIP-C (with the exception of Distant [DE]). While this pattern of correlations may be due to rotational differences, it is important to note that the IAS-R describes portions of the IPC with mostly socially undesirable or maladaptive trait terms. For example, IASR Arrogant-Calculating (BC) consists of "calculating," "crafty," and "cunning," and Cold-Hearted (DE) includes "cruel," "ironhearted," and "ruthless." Thus, at least some IAS-R subscales already have some maladaptive content built into them. However, compared to the CSIP and IIP-C, these regions of the IPC are operationalized differently. Whereas the IAS-R defines (BC) and (DE) in mostly manipulative and hostile terms, the CSIP and IIP-C define this space with selfish (BC) and emotionally distant (DE) behavior. While individuals who score high on the trait scales may indeed experience difficulty establishing and maintaining prosocial relationships, those who are unable to successfully form close and lasting relationships are not necessarily manipulative or hostile. Thus, even though some interpersonal measures like the IAS-R may include maladaptive content, these measures may not be structurally equivalent with measures explicitly designed to assess dysfunctional interpersonal behavior. And while scales not originally constructed to measure pathology do often show significant associations with relative external measures (as do other basic scales in other domains, e.g., Big Five/FFM), these scales are generally not understood as substitute measures of interpersonal problems.

However, a multimethod approach to personality assessment that focuses on a variety of different domains or levels of functioning (e.g., traits, problems, values, strengths, sensitivities) can provide valuable information for understanding behavior (Dawood \& Pincus, 2016; Pincus et 
al., 2014). Because most modern IPC measures use the same octant structure, they can be scored to create a "multisurface" interpersonal profile. Recent clinical case applications have demonstrated the value of this approach in providing insight into the structural dynamics of an individual's personality. For example, Pincus et al. (2014) presented a case of a young adult man who suffered from depression. He viewed himself as cold and aloof (traits) and felt distressed by his behavior (problems), but valued social avoidance as a coping strategy. He also indicated that warm and extraverted behavior were important to him (values), though he didn't believe he was particularly good at enacting these behaviors (strengths) and felt sensitive when others acted cold or distant toward him (sensitivities). Together, a multimethod assessment strategy can help identify a number of intrapsychic conflicts that can provide a context for therapists to understand and treat their clients' complaints. Although this approach benefits from multiple surfaces, it relies on the need for direct assessments of problems to contrast with other levels of personality functioning.

Given that the CSIP and IIP-C were designed to measure problematic interpersonal behavior, it should not be surprising to find some overlap in item content. For example, both measures include problems with being too controlling and manipulative (Domineering [PA]), selfish (Self-Centered [BC]), and respectful of other people's boundaries (Intrusive [NO]). The fact that some parallel items exist between the two measures is to be expected, and should help quell any concerns that the measures are non-equivalent, both empirically and at face value. However, the majority of items are different in content and wording. One of the values of the CSIP is its description of new (albeit related) problems within each region of the circle. For example, the CSIP adds arrogant, condescending, and overly bossy behavior to Domineering (PA), an inability to feel remorseful, respectful, and considerate toward others to Self-Centered (BC), and excessive flirtatiousness, talkativeness, and exaggeration to Intrusive (NO). Similarly, the IIP-C 
includes content not contained within the CSIP. By sampling different problems within similar regions of the IPC, the CSIP helps extend the range of behavioral exemplars of the underlying constructs, and thus increments coverage of interpersonal difficulties.

While multiple measures of the same constructs are useful, it is unlikely that they would be equally valid for all purposes. For example, by comparing the components of variance explained (presented in Table 9), both the CSIP and IIP-C predicted unique variance in a range of outcomes, but neither measure demonstrated superior evidence of predictive validity across all outcomes. But while the CSIP and IIP-C were similar in terms of their average validity, they showed differences in their validities for individual criteria. In part, this may be due to differences in item content. CSIP items, for example, appear slightly better at capturing aspects of high Extraversion, whereas IIP-C items appear slightly better at capturing high Agreeableness. Researchers interested in specific forms of high Extraversion- or high Agreeableness-related distress (e.g., histrionic vs. dependent personality disorders, approach vs. avoidance conflicts) might choose one instrument over the other. Moreover, the CSIP was more strongly related to depression and negative affect than the IIP-C, suggesting that the CSIP may be the measure of choice for researchers interested in studying the interpersonal aspects of depression or other mood disorders (e.g., Vittengl, Clark, $\&$ Jarrett, 2003). These results are similar to other studies that compared the predictive validity of multiple measures of the same constructs. Grucza and Goldberg (2007) compared the validity of 11 personality inventories in predicting a range of behavioral and clinical outcomes. They reported that although the average cross-validity coefficients were similar across instruments, measures that did not perform well against some criteria were superior in predicting other criteria. By identifying areas in which the CSIP and IIP-C do well, researchers could make informed decisions of which measure suits their needs best. The availability of multiple measures affords such an opportunity. 
An additional consideration for future research is whether the research questions warrant the inclusion of one or both interpersonal problems measures. At least with the current set of validators, incremental prediction of outcomes by the CSIP and IIP-C were generally $<10 \%$. Researchers will need to weigh the potential increment in predictive power against the burden of doubling the interpersonal problem items, from 64 when using one measure to 128 when using both. If the research question is focused on interpersonal functioning, using both measures may be warranted. However, if there is an alternative focus, and the interpersonal problems measure is being included for coverage of the interpersonal domain as part of a larger comprehensive battery, then choosing between measures is probably preferable. As an alternative approach, because the CSIP and IIP-C have some degree of overlapping content, researchers may wish to decompose and combine the non-overlapping items of one measure with the full set of items from the other. This would, presumably, provide maximal content coverage with the fewest number of items and a minimal amount of redundancy. We would encourage researchers considering this approach, however, to take care in evaluating the circumplexity of any ad hoc composition of items.

Some limitations should be kept in mind when interpreting the present results. Most importantly, interpersonal problems were measured using self-reports and are therefore susceptible to subjective biases. While some evidence indicates that self-reports of interpersonal problems converge with peer reports, peer ratings provide an alternative point of view that may explain unique variation in some outcomes (Clifton, Turkheimer, \& Oltmanns, 2005). An additional limitation concerns the nature of the two samples, which were both college student samples. The focus here was on the structure of dimensional constructs and their patterns of relations with other variables, which may not differ substantially from other non-student samples. However, it will be important to examine how the CSIP operates in clinical and community samples. Future research 
could add to these findings by examining informant ratings of targets' problems, as well as base rates of problem occurrence in other age groups, in both normal and treatment-seeking populations. Additional research would help clarify the comparative strengths and limitations of the CSIP and IIP-C, which we hope will enhance construct validity and the decision making process.

In summary, the CSIP provides a comprehensive and highly efficient means for characterizing interpersonal problems. It can be used as an alternative to the IIP-C, where the cost of administration may prohibit the use of interpersonal problems measures. It could also be used in conjunction with the IIP-C to cover the range of interpersonal difficulties more thoroughly, particularly in studies where interpersonal problems is a primary focus. The CSIP may provide a welcome alternative to other social functioning measures, which tend to focus primarily on the amount of social interaction rather than its quality, which may not accurately reflect the kinds of impairments that are frequently associated with personality disorders (Oltmanns, Melley, \& Turkheimer, 2002). Indeed, many of the most important questions about personality are concerned with its connection to real life outcomes, ranging from social adjustment to health and mortality (Ozer \& Benet-Martinez, 2006). In the realm of social adjustment, there is a serious need for valid, more broadly based questionnaires that tap a range of problems associated with personality traits, which the CSIP aims to accomplish. The CSIP will provide a useful tool for investigators who study the interpersonal consequences of personality and psychopathology (Pincus \& Wright, 2011). It may also become a valuable outcome measure for treatment studies that focus on broad outcomes, including social functioning, rather than simply the remission of specific symptoms. 


\section{References}

Acton, G. S., \& Revelle, W. (2002). Interpersonal personality measures show circumplex structure based on new psychometric criteria. Journal of Personality Assessment, 79, 446-471.

Alden, L. E., Wiggins, J. S., \& Pincus, A. L. (1990). Construction of circumplex scales for the Inventory of Interpersonal Problems. Journal of Personality Assessment, 55, 521-536.

Bartholomew, K., \& Horowitz, L. M. (1991). Attachment styles among young adults: A test of a four-category model. Journal of Personality and Social Psychology, 61, 226-244.

Bateman, A., \& Fonagy, P. (1999). Effectiveness of partial hospitalization in the treatment of borderline personality disorder: A randomized controlled trial. American Journal of Psychiatry, 156, 1563-1569.

Block, J. (1961). The Q-sort method in personality assessment and psychiatric research. Springfield, IL: Charles C. Thomas.

Block, J. (2008). The Q-sort in character appraisal: Encoding subjective impressions of persons quantitatively. Washington, DC: American Psychological Association.

Boudreaux, M. J. (2016). Personality-related problems and the five-factor model of personality. Personality Disorders: Theory, Research, and Treatment, 7, 372-383.

Boudreaux, M. J., Piedmont, R. L., Sherman, M. F., \& Ozer, D. J. (2013). Identifying personalityrelated problems in living: The multi-context problems checklist. Journal of Personality Assessment, 95, 62-73.

Brown, L. S., \& Wright, J. (2003). The relationship between attachment strategies and psychopathology in adolescence. Psychology and Psychotherapy: Theory, Research and Practice, 76, 351-367.

Browne, M. W. (1992). Circumplex models for correlation matrices. Psychometrika, 57, 469-497. 
Clark, L. A. (1993). Manual for the Schedule for Nonadaptive and Adaptive Personality. Minneapolic, MN: University of Minnesota Press.

Clifton, A., Turkheimer, E., \& Oltmanns, T. F. (2005). Self- and peer perspectives on pathological personality traits and interpersonal problems. Psychological Assessment, 17, 123-131.

Costa, P. T., Jr., \& McCrae, R. R. (1992). Manual for the Revised NEO Personality Inventory and NEO Five-Factor Inventory. Odessa, FL: Psychological Assessment Resources.

Dawood, S., \& Pincus, A. L. (2016). Multisurface interpersonal assessment in a cognitivebehavioral therapy context. Journal of Personality Assessment, 98, 449-460.

De Raad, B., \& Perugini, M. (2002). Big five assessment. Seattle, WA: Hogrefe \& Huber.

Derogatis, L. R. (2000). The Brief Symptom Inventory-18: Administration, scoring, and procedures manual ( $3^{\text {rd }}$ ed.). Minneapolic, MN: National Computer Systems, Pearson.

Fabrigar, L. R., Visser, P. S., \& Browne, M. W. (1997). Conceptual and methodological issues in testing the circumplex structure of data in personality and social psychology. Personality and Social Psychology Review, 1, 184-203.

Gaines, S. O., Jr., Panter, A. T., Lyde, M. D., Steers, W. N., Rusbult, C. E., Cox, C. L., \& Wexler, M. O. (1997). Evaluating the circumplexity of interpersonal traits and the manifestation of interpersonal traits in interpersonal trust. Journal of Personality and Social Psychology, $73,610-623$.

Goldberg, L. R. (1982). From Ace to Zombie: Some explorations in the language of personality. In C. D. Spielberger \& J. N. Butcher (Eds.), Advances in personality assessment (Vol. 1., pp. 203-234). Hillsdale, NJ: Erlbaum.

Goldberg, L. R. (1992). The development of markers for the Big-Five factor structure. Psychological Assessment, 4, 26-42. 
Goldberg, L. R. (1999). A broad-bandwidth, public domain, personality inventory measuring the lower-level facets of several five-factor models. In I. Mervielde, I. Deary, F. Fruyt, \& F. Ostendorf (Eds.), Personality psychology in Europe (Vol. 7, pp. 7-28). Tilburg, the Netherlands: Tilburg University Press.

Goldberg, L. R., Johnson, J. A., Eber, H. W., Hogan, R., Ashton, M. C., Cloninger, C. R., \& Gough, H. G. (2006). The international personality item pool and the future of public-domain personality measures. Journal of Research in Personality, 40, 84-96.

Gosling, S. D., Rentfrow, P. J., \& Swann, W. B., Jr. (2003). A very brief measure of the big-five personality domains. Journal of Research in Personality, 37, 504-528.

Grassi, M., Luccio, R., \& Di Blas, L. (2010). CircE: An R implementation of Browne's circular stochastic process model. Behavior Research Methods, 42, 55-73.

Grucza, R. A., \& Goldberg, L. R. (2007). The comparative validity of 11 modern personality inventories: Predictions of behavioral acts, informant reports, and clinical indicators. Journal of Personality Assessment, 89, 167-187.

Guadagnoli, E., \& Velicer, W. (1991). A comparison of pattern matching indices. Multivariate Behavioral Research, 26, 323-343.

Gurtman, M. B. (1992a). Construct validity of interpersonal personality measures: The interpersonal circumplex as a nomological net. Journal of Personality and Social Psychology, 63, 105-118.

Gurtman, M. B. (1992b). Trust, distrust, and interpersonal problems: A circumplex analysis. Journal of Personality and Social Psychology, 62, 989-1002. 
Gurtman, M. B. (1994). The circumplex as a tool for studying normal and abnormal personality: A methodological primer. In S. Strack \& M. Lorr (Eds.), Differentiating normal and abnormal personality (pp. 243-263). New York, NY: Springer.

Gurtman, M. B., \& Pincus, A. L. (2000). Interpersonal adjective scales: Confirmation of circumplex structure from multiple perspectives. Personality and Social Psychology Bulletin, 26, 374-384.

Gurtman, M. B., \& Pincus, A. L. (2003). The circumplex model: Methods and research applications. In J. A. Schinka \& W. F. Velicer (Eds.), Handbook of psychology: Research methods in psychology (Vol. 2, pp. 407-428). Hoboken, NJ: Wiley.

Guttman, L. (1954). A new approach to factor analysis: The radix. In P. F. Lazarsfeld (Ed.), Mathematical thinking in the social sciences (pp. 258-348). Glencoe, IL: Free Press.

Harkness, A. R., \& McNulty, J. L. (1994). The Personality Psychopathology Five (PSY-5): Issues from the pages of a diagnostic manual instead of a dictionary. In S. Strack \& M. Lorr (Eds.), Differentiating normal and abnormal personality (pp. 291-315). New York, NY: Springer.

Hofstee, W. K. B., De Raad, B., \& Goldberg, L. R. (1992). Integration of the big five and circumplex approaches to trait structure. Journal of Personality and Social Psychology, 63, 146-163.

Hopwood, C. L., Koonce, E. A., \& Morey, L. C. (2009). An exploratory study of integrative personality pathology systems and the interpersonal circumplex. Journal of Psychopathology and Behavioral Assessment, 31, 331-339.

Horney, K. (1945). Our inner conflicts. New York, NY: Norton.

Horowitz, L. M. (1979). On the cognitive structure of interpersonal problems treated in psychotherapy. Journal of Consulting and Clinical Psychology, 47, 5-15. 
Horowitz, L. M., Alden, L. E., Wiggins, J. S., \& Pincus, A. L. (2000). Manual for the inventory of interpersonal problems. San Antonio, TX: Psychological Corporation.

Horowitz, L. M., Rosenberg, S. E., Baer, B. A., Ureño, G., \& Villaseñor, V. S. (1988). Inventory of interpersonal problems: Psychometric properties and clinical applications. Journal of Consulting and Clinical Psychology, 56, 885-892.

Horowitz, L. M., Rosenberg, S. E., \& Bartholomew, K. (1993). Interpersonal problems, attachment styles, and outcome in brief dynamic psychotherapy. Journal of Consulting and Clinical Psychology, 61, 549-560.

Horowitz, L. M., Sampson, H., Siegelman, E. Y., Weiss, J., \& Goodfriend, S. (1978). Cohesive and dispersal behaviors: Two classes of concomitant change in psychotherapy. Journal of Consulting and Clinical Psychology, 46, 556-564.

Horowitz, L. M., \& Vitkus, J. (1986). The interpersonal basis of psychiatric symptoms. Clinical Psychology Review, 6, 443-469.

Horowitz, L. M., Weckler, D. A., \& Doren, R. (1983). Interpersonal problems and symptoms: A cognitive approach. In P. Kendall (Ed.), Advances in cognitive-behavioral research and therapy (pp. 81-125). London: Academic Press.

John, O. P., Donahue, E., M., \& Kentle, R. L. (1991). The Big Five Inventory - Versions $4 a$ and 54. Berkeley, CA: University of California, Berkeley, Institute of Personality and Social Research.

Johnson, J. A. (2014). Measuring thirty facets of the five factor model with a 120 -item public domain inventory: Development of the IPIP-NEO-120. Journal of Research in Personality, $51,78-89$. 
Krueger, R. F., Derringer, J., Markon, K. E., Watson, D., \& Skodol, A. E. (2012). Initial construction of a maladaptive personality trait model and inventory for DSM-5. Psychological Medicine, 42, 1879-1890.

Leary, T. (1957). Interpersonal diagnosis of personality. New York: Ronald.

Livesley, W. J., \& Jackson, D. (2009). Manual for the Dimensional Assessment of Personality Pathology - Basic Questionnaire. Port Huron, MI: Sigma Press.

Locke, K. D. (2011). Circumplex measures of interpersonal constructs. In L. M. Horowitz \& S. Strack (Eds.), Handbook of interpersonal psychology: Theory, research, assessment, and therapeutic interventions. Hoboken, NJ: Wiley.

Maples, J. L., Guan, L., Carter, N. T., \& Miller, J. D. (2014). A test of the international personality item pool representation of the Revised NEO Personality Inventory and development of a 120-item IPIP-based measure of the five-factor model. Psychological Assessment, 26, 1070-1084.

McCrae, R. R., \& Costa, P. T., Jr. (1989). The structure of interpersonal traits: Wiggins's circumplex model and the five-factor model. Journal of Personality and Social Psychology, 56, 586-595.

McCrae, R. R., \& Costa, P. T., Jr. (2010). NEO Inventories professional manual. Lutz, FL: Psychological Assessment Resources.

Oltmanns, T. F., Melley, A. H., \& Turkheimer, E. (2002). Impaired social functioning and symptoms of personality disorders assessed by peer and self-report in a nonclinical population. Journal of Personality Disorders, 16, 437-452.

Ozer, D. J., \& Benet-Martinez, V. (2006). Personality and the prediction of consequential outcomes. Annual Review of Psychology, 57, 401-421. 
Pincus, A.L., Sadler, P., Woody, E., Roche, M.J., Thomas, K.M., \& Wright, A.G.C., (2014). Multimethod assessment of interpersonal dynamics. In C. J. Hopwood \& R. F. Bornstein (Eds.), Multimethod clinical assessment (pp. 51-91). New York, NY: Guilford Press.

Pincus, A. L., \& Wright, A. G. C. (2011). Interpersonal diagnosis of psychopathology. In L. M. Horowitz \& S. Strack (Eds.), Handbook of interpersonal psychology: Theory, research, assessment, and therapeutic interventions. Hoboken, NJ: Wiley.

Przeworski, A., Newman, M. G., Pincus, A. L., Kasoff, M. B., Yamasaki, A. S., Castonguay, L. G., \& Berlin, K. S. (2011). Interpersonal pathoplasticity in individuals with generalized anxiety disorder. Journal of Abnormal Psychology, 120, 286-298.

Rammstedt, B., \& John, O. P. (2007). Measuring personality in one minute or less: A 10-item short version of the Big Five Inventory in English and German. Journal of Research Personality, 41, 203-212.

Rounds, J. Tracey, T. J., \& Hubert, L. (1992). Methods for evaluating vocational interest structural hypotheses. Journal of Vocational Behavior, 40, 239-259.

Shafer, A. B. (2006). Meta-analysis of the factor structures of four depression questionnaires: Beck, CES-D, Hamilton, and Zung. Journal of Clinical Psychology, 62, 123-146.

Soldz, S., Budman, S., Demby, A., \& Merry, J. (1995). A short form of the inventory of the inventory of Circumplex Scales of Interpersonal Problems. Assessment, 2, 53-63.

Soto, C. J., \& John, O. P. (in press). The next Big Five Inventory (BFI-2): Developing and assessing a hierarchical model with 15 facets to enhance bandwidth, fidelity, and predictive power. Journal of Personality and Social Psychology.

Sullivan, H. S. (1953). The interpersonal theory of psychiatry. New York: Norton. 
Wiggins, J.S. (1995). Interpersonal Adjective Scales: Professional manual. Odessa, FL: Psychological Assessment Resources.

Wiggins, J. S., \& Broughton, R. (1991). A geometric taxonomy of personality scales. European Journal of Personality, 5, 343-365.

Wiggins, J. S., Phillips, N., \& Trapnell, P. (1989). Circular reasoning about interpersonal behavior: Evidence concerning some untested assumptions underlying diagnostic classification. Journal of Personality and Social Psychology, 56, 296-305.

Wiggins, J. S., Steiger, J. H., \& Gaelick, L. (1981). Evaluating circumplexity in personality data. Multivariate Behavioral Research, 16, 263-289.

Wiggins, J. S., Trapnell, P., \& Phillips, N. (1988). Psychometric and geometric characteristics of the revised Interpersonal Adjective Scales (IAS-R). Multivariate Behavioral Research, 23, 517-530.

Wright, A. G. C., Hallquist, M. N., Morse, J. Q., Scott, L. N., Stepp, S. D., Nolf, K. A., \& Pilkonis, P. A. (2013). Clarifying interpersonal heterogeneity in borderline personality disorder using latent mixture modeling. Journal of Personality Disorders, 27, 125-143.

Wright, A. G. C., Pincus, A. L., Conroy, D. E., \& Hilsenroth, M. J. (2009). Integrating methods to optimize circumplex description and comparison of groups. Journal of Personality Assessment, 91, 311-322.

Wright, A. G. C., Thomas, K. M., Hopwood, C. J., Markon, K. E., Pincus, A. L., \& Krueger, R. F. (2012). The hierarchical structure of DSM-5 pathological personality traits. Journal of Abnormal Psychology, 121, 951-957. 
Vittengl, J. R., Clark, L. E., \& Jarrett, R. B. (2003). Interpersonal problems, personality pathology, and social adjustment after cognitive therapy for depression. Psychological Assessment, 15, 29-40.

Zimmermann, J., \& Wright, A. G. C. (2017). Beyond description in interpersonal construct validation: Methodological advances in the circumplex structural summary approach. Assessment, 24, 3-23. 
Table 1

Descriptive Statistics for the CSIP - Overall and Separated by Gender

\begin{tabular}{lrrrrrr}
\hline & Women $^{\mathrm{a}}$ & \multicolumn{2}{c}{ Men $^{\mathrm{b}}$} & & \multicolumn{3}{c}{ Overall $^{\mathrm{c}}$} \\
\cline { 2 - 3 } \cline { 6 - 7 } CSIP & $M(S D)$ & $M(S D)$ & $t$ & $d^{\mathrm{d}}$ & $M(S D)$ & $\alpha$ \\
\hline Domineering (PA) & $2.5(3.3)$ & $3.8(4.7)$ & $-2.24^{*}$ & -.35 & $3.0(3.9)$ & .87 \\
Self-Centered (BC) & $3.0(3.6)$ & $3.5(3.7)$ & -0.88 & -.14 & $3.2(3.8)$ & .83 \\
Distant (DE) & $6.2(4.8)$ & $5.3(5.0)$ & 1.20 & .19 & $5.6(5.1)$ & .87 \\
Socially Inhibited (FG) & $7.9(5.7)$ & $7.4(5.2)$ & 0.66 & .09 & $7.2(5.5)$ & .89 \\
Nonassertive (HI) & $7.9(5.0)$ & $5.9(4.8)$ & $2.74^{* *}$ & .41 & $7.1(5.1)$ & .86 \\
Exploitable (JK) & $7.3(4.5)$ & $5.7(4.6)$ & $2.29^{*}$ & .35 & $6.5(4.6)$ & .84 \\
Self-Sacrificing (LM) & $8.1(4.6)$ & $6.0(4.3)$ & $3.05^{* *}$ & .47 & $7.4(4.7)$ & .82 \\
Intrusive (NO) & $4.7(3.8)$ & $4.7(4.4)$ & 0.04 & .00 & $4.7(4.0)$ & .79 \\
Total (TOT) & $47.6(23.2)$ & $42.3(26.5)$ & 1.44 & .22 & $44.7(25.6)$ & --- \\
\hline
\end{tabular}

Note. ${ }^{\mathrm{a}} n=121 ;{ }^{\mathrm{b}} n=70 ;{ }^{\mathrm{c}} n=712$; ${ }^{\mathrm{d}} \mathrm{Effect}$ size for gender difference. Scale range is 0 to 24 for octant scales; 0 to 192 for total score.

${ }^{* *} p<.01, \stackrel{*}{p} p<.05 ;$ two-tailed. 
Table 2

Correlations among the CSIP Scales

\begin{tabular}{lrrrrrrrr}
\hline CSIP & PA & BC & DE & FG & HI & JK & LM & NO \\
\hline Domineering (PA) & --- & .70 & .39 & .18 & .14 & .21 & .20 & .62 \\
Self-Centered (BC) & .47 & --- & .60 & .43 & .33 & .30 & .13 & .48 \\
Distant (DE) & -.08 & .18 & --- & .66 & .52 & .40 & .20 & .24 \\
Socially Inhibited (FG) & -.40 & -.13 & .21 & --- & .71 & .52 & .27 & .13 \\
Nonassertive (HI) & -.59 & -.43 & -.15 & .25 & --- & .78 & .47 & .25 \\
Exploitable (JK) & -.44 & -.50 & -.39 & -.15 & .41 & --- & .64 & .40 \\
Self-Sacrificing (LM) & -.16 & -.45 & -.45 & -.37 & -.12 & .25 & --- & .45 \\
Intrusive (NO) & .38 & .10 & -.35 & -.56 & -.44 & -.16 & .12 & --- \\
\hline
\end{tabular}

Note. $N=712$. Correlations $\geq .15, p<.001$; two-tailed. Correlations above the diagonal are based on raw scores; correlations below the diagonal are based on ipsatized scores. 
Table 3

Summary of Model Fit Tests of the Circular Correlational Structure of the CSIP

\begin{tabular}{|c|c|c|c|c|c|c|c|c|c|c|}
\hline \multirow[b]{2}{*}{ Sample } & \multirow[b]{2}{*}{$N$} & \multicolumn{2}{|c|}{ Model } & \multirow[b]{2}{*}{$d f$} & \multirow[b]{2}{*}{$K$} & \multicolumn{5}{|c|}{ Goodness-of-Fit Measures } \\
\hline & & Spacing & Communality & & & RMSEA & RMSEA 90\% CI & $C F I$ & $N N F I$ & $B I C$ \\
\hline \multirow[t]{3}{*}{ Scale Development } & 1,137 & Equal & Equal & 24 & 12 & .100 & {$[.090 ; .110]$} & .96 & .95 & .188 \\
\hline & & Unequal & Equal & 17 & 19 & .079 & {$[.067 ; .092]$} & .98 & .97 & .004 \\
\hline & & Equal & Unequal & 17 & 19 & .090 & {$[.078 ; .102]$} & .98 & .96 & .034 \\
\hline \multirow[t]{3}{*}{ Validation } & 712 & Equal & Equal & 24 & 12 & .114 & {$[.102 ; .128]$} & .93 & .92 & .237 \\
\hline & & Unequal & Equal & 17 & 19 & .083 & {$[.067 ; .099]$} & .98 & .96 & -.036 \\
\hline & & Equal & Unequal & 17 & 19 & .093 & {$[.077 ; .108]$} & .96 & .95 & -.006 \\
\hline
\end{tabular}

Note. Analyses conducted with R Package CircE (Grassi et al., 2010) using models outlined in Browne (1992). $d f=$ degrees of freedom; $K=$ parameters; $R M S E A$ $=$ Root Mean Square Error of Approximation; $C F I=$ Comparative Fit Index; $N N F I=$ Non-Normed Fit Index. 
Table 4

Correlations of the CSIP with the IIP-C

\begin{tabular}{lrrrrrrrr}
\hline & \multicolumn{1}{c}{ CSIP } \\
\cline { 2 - 8 } IIP-C & PA & BC & DE & FG & HI & JK & LM & NO \\
\hline Domineering (PA) & .66 & .45 & .02 & -.25 & -.55 & -.46 & -.10 & .35 \\
Self-Centered (BC) & .48 & .58 & .15 & -.16 & -.46 & -.42 & -.24 & .22 \\
Distant (DE) & .12 & .33 & .66 & .12 & -.27 & -.42 & -.39 & -.14 \\
Socially Inhibited (FG) & -.32 & -.07 & .30 & .73 & .35 & -.12 & -.41 & -.55 \\
Nonassertive (HI) & -.50 & -.35 & -.10 & .18 & .66 & .45 & -.02 & -.37 \\
Exploitable (JK) & -.36 & -.38 & -.34 & -.10 & .39 & .60 & .30 & -.16 \\
Self-Sacrificing (LM) & -.12 & -.38 & -.32 & -.29 & -.03 & .32 & .63 & .10 \\
Intrusive (NO) & .28 & .00 & -.33 & -.39 & -.34 & -.11 & .22 & .70 \\
\hline
\end{tabular}

Note. $N=700$. Correlations $\geq .15, p<.001$; two-tailed. $\mathrm{PA}=$ Domineering; $\mathrm{BC}=$ Selfish; $\mathrm{DE}=\mathrm{Distant} ; \mathrm{FG}=$ Socially Inhibited; $\mathrm{HI}=$ Nonassertive; $\mathrm{JK}=$ Exploitable; $\mathrm{LM}=$ Self-Sacrificing; $\mathrm{NO}=$ Intrusive. 
Table 5

Joint Analysis of the CSIP and IIP-C Scales: Rotated Component Loadings, Communalities, and Angular Locations for Component Plot

\begin{tabular}{lrrrrrr}
\hline & \multicolumn{3}{c}{ Loadings } & & & \\
\cline { 2 - 3 } & Factor 1 & Factor 2 & & $h^{2}$ & Displacement & Difference $^{\mathrm{a}}$ \\
\hline Domineering (PA) & & & & & \\
$\quad$ CSIP & -.07 & .78 & .61 & $95.1^{\circ}\left(90^{\circ}\right)$ & $5.1^{\circ}$ \\
IIP-C & -.16 & .78 & .63 & $101.6^{\circ}\left(90^{\circ}\right)$ & $11.6^{\circ}$ \\
Self-Centered (BC) & & & & & \\
$\quad$ CSIP & -.45 & .56 & .52 & $128.8^{\circ}\left(135^{\circ}\right)$ & $6.2^{\circ}$ \\
IIP-C & -.38 & .65 & .56 & $120.3^{\circ}\left(135^{\circ}\right)$ & $14.7^{\circ}$ \\
Distant (DE) & & & & & & \\
CSIP & -.70 & -.02 & .50 & $181.6^{\circ}\left(180^{\circ}\right)$ & $1.6^{\circ}$ \\
IIP-C & -.70 & .20 & .53 & $164.1^{\circ}\left(180^{\circ}\right)$ & $15.9^{\circ}$ \\
Socially Inhibited (FG) & & & & & \\
CSIP & -.55 & -.51 & .56 & $222.8^{\circ}\left(225^{\circ}\right)$ & $2.2^{\circ}$ \\
IIP-C & -.63 & -.52 & .66 & $219.5^{\circ}\left(225^{\circ}\right)$ & $5.5^{\circ}$ \\
Nonassertive (HI) & & & & & \\
CSIP & .05 & -.78 & .62 & $273.7^{\circ}\left(270^{\circ}\right)$ & $3.7^{\circ}$ \\
IIP-C & .11 & -.76 & .58 & $278.2^{\circ}\left(270^{\circ}\right)$ & $8.2^{\circ}$ \\
Exploitable (JK) & & & & & \\
CSIP & .54 & -.53 & .58 & $315.5^{\circ}\left(315^{\circ}\right)$ & $0.5^{\circ}$ \\
IIP-C & .54 & -.53 & .57 & $315.5^{\circ}\left(315^{\circ}\right)$ & $0.5^{\circ}$ \\
Self-Sacrificing (LM) & & & & & \\
CSIP & .74 & .00 & .54 & $360.0^{\circ}\left(360^{\circ}\right)$ & $0.0^{\circ}$ \\
IIP-C & .71 & -.08 & .51 & $353.6^{\circ}\left(360^{\circ}\right)$ & $6.4^{\circ}$ \\
Intrusive (NO) & & & & & \\
CSIP & .43 & .66 & .62 & $56.9^{\circ}\left(45^{\circ}\right)$ & $11.9^{\circ}$ \\
IIP-C & .46 & .57 & .53 & $51.1^{\circ}\left(45^{\circ}\right)$ & $6.1^{\circ}$ \\
Average & & & & & \\
CSIP & --- & --- & .57 & & $3.9^{\circ}$ \\
IIP-C & --- & --- & .57 & & $-6^{\circ}$ \\
\hline
\end{tabular}

Note. $N=700$. ${ }^{\text {a } A b s o l u t e ~ d i f f e r e n c e ~ v a l u e s ~ b e t w e e n ~ o b s e r v e d ~ a n d ~ t h e o r e t i c a l ~ a n g u l a r ~ l o c a t i o n s . ~}$ 
Table 6

Correlations of the CSIP with the IAS-R

\begin{tabular}{lrrrrrrrr}
\hline & \multicolumn{7}{c}{ CSIP } \\
\cline { 2 - 8 } IAS-R & PA & BC & DE & FG & HI & JK & LM & NO \\
\hline Assured-Dominant (PA) & .57 & .36 & .03 & -.34 & -.63 & -.33 & .03 & .42 \\
Arrogant-Calculating (BC) & .39 & .36 & .13 & -.12 & -.31 & -.25 & -.26 & .18 \\
Cold-Hearted (DE) & .29 & .51 & .27 & .04 & -.25 & -.33 & -.37 & -.03 \\
Aloof-Introverted (FG) & -.15 & .17 & .38 & .48 & .12 & -.19 & -.41 & -.42 \\
Unassured-Submissive (HI) & -.47 & -.22 & .10 & .48 & .57 & .21 & -.25 & -.49 \\
Unassuming-Ingenuous (JK) & -.28 & -.12 & .09 & .21 & .20 & .12 & .00 & -.26 \\
Warm-Agreeable (LM) & -.28 & -.44 & -.28 & -.06 & .21 & .33 & .41 & .00 \\
Gregarious-Extraverted (NO) & .09 & -.14 & -.32 & -.44 & -.13 & .20 & .35 & .41 \\
\hline
\end{tabular}

Note. $N=696$. Correlations $\geq .15, p<.001$; two-tailed. $\mathrm{PA}=$ Domineering; $\mathrm{BC}=$ Self-Centered; $\mathrm{DE}=$ Distant; $\mathrm{FG}=$ Socially Inhibited; HI = Nonassertive; JK = Exploitable; LM = Self-Sacrificing; NO = Intrusive. 
Table 7

CSIP and IIP-C Structural Summary Parameters for BFI-2 Scales

\begin{tabular}{|c|c|c|c|c|c|c|c|c|}
\hline \multirow[b]{2}{*}{ BFI-2 } & \multicolumn{4}{|c|}{ CSIP } & \multicolumn{4}{|c|}{ IIP-C } \\
\hline & Elevation $[\mathrm{CI}]$ & Amplitude [CI] & Angle [CI] & $R^{2}$ & Elevation $[\mathrm{CI}]$ & Amplitude [CI] & Angle [CI] & $R^{2}$ \\
\hline \multicolumn{9}{|l|}{ Domains } \\
\hline Extraversion & $-.24[-.29,-.20]$ & $.41[.37, .45]$ & $59.3[54.1,64.9]$ & .99 & $-.23[-.28,-.19]$ & $.34[.30, .38]$ & $65.8[58.1,73.1]$ & .97 \\
\hline Agreeableness & $-.24[-.29,-.19]$ & $.29[.24, .34]$ & $308.9[300.5,317.8]$ & .95 & $-.23[-.28,-.18]$ & $.37[.32, .41]$ & $311.2[305.7,317.1]$ & .99 \\
\hline Conscientiousness & $-.18[-.23,-.14]$ & $.03[.01, .08]$ & $51.2[307.4,158.1]$ & .15 & $-.17[-.22,-.12]$ & $.03[.01, .09]$ & $349.4[268.5,110.4]$ & .22 \\
\hline Neuroticism & $.32[.27, .36]$ & $.14[.10, .18]$ & $264.4[248.5,280.5]$ & .92 & $.29[.25, .34]$ & $.06[.03, .11]$ & $248.1[203.4,283.6]$ & .53 \\
\hline Openness to Experience & $-.04[-.09, .01]$ & $.01[.01, .07]$ & $91.2[286.3,252.0]$ & .03 & $-.04[-.09, .01]$ & $.02[.01, .07]$ & $22.6[263.6,158.3]$ & .19 \\
\hline \multicolumn{9}{|l|}{ Extraversion Facets } \\
\hline Social Engagement & $-.20[-.24,-.15]$ & $.39[.36, .43]$ & $51.3[44.6,57.6]$ & .96 & $-.18[-.22,-.13]$ & $.32[.28, .35]$ & $58.9[49.8,67.1]$ & .92 \\
\hline Assertiveness & $-.16[-.21,-.12]$ & $.37[.33, .41]$ & $82.1[75.7,88.5]$ & .97 & $-.17[-.22,-.12]$ & $.35[.31, .39]$ & $90.7[83.8,97.8]$ & .99 \\
\hline Energy Level & $-.23[-.28,-.18]$ & $.26[.22, .30]$ & $38.1[27.9,47.9]$ & .99 & $-.22[-.27,-.17]$ & $.20[.17, .24]$ & $30.8[16.8,44.6]$ & .95 \\
\hline \multicolumn{9}{|l|}{ Agreeableness Facets } \\
\hline Compassion & $-.14[-.19,-.08]$ & $.29[.25, .34]$ & $314.2[306.1,323.1]$ & .93 & $-.14[-.19,-.09]$ & $.33[.29, .37]$ & $315.9[309.3,322.6]$ & .98 \\
\hline Respectfulness & $-.21[-.26,-.15]$ & $.27[.23, .32]$ & $291.6[282.9,300.6]$ & .96 & $-.18[-.23,-.13]$ & $.35[.31, .38]$ & $299.4[292.9,306.1]$ & .98 \\
\hline Acceptance of Others & $-.24[-.28,-.19]$ & $.17[.13, .22]$ & $323.6[309.1,338.9]$ & .94 & $-.23[-.28,-.19]$ & $.24[.19, .28]$ & $319.6[310.7,328.9]$ & .99 \\
\hline \multicolumn{9}{|l|}{ Conscientiousness Facets } \\
\hline Organization & $-.08[-.13,-.03]$ & $.01[.00, .06]$ & $116.5[306.1,278.5]$ & .01 & $-.08[-.13,-.03]$ & $.01[.00, .06]$ & $294.4[125.5,104.9]$ & .02 \\
\hline Productiveness & $-.18[-.24,-.14]$ & $.10[.05, .14]$ & $87.5[61.0,115.7]$ & .76 & $-.16[-.21,-.10]$ & $.07[.03, .12]$ & $90.5[39.7,126.8]$ & .56 \\
\hline Responsibility & $-.19[-.24,-.14]$ & $.07[.03, .12]$ & $325.7[284.1,10.3]$ & .41 & $-.19[-.24,-.14]$ & $.11[.07, .16]$ & $320.0[300.4,340.4]$ & .83 \\
\hline \multicolumn{9}{|l|}{ Neuroticism Facets } \\
\hline Anxiety & $.24[.19, .28]$ & $.14[.10, .18]$ & $266.8[250.9,281.3]$ & .95 & .26] & $3, .12]$ & $270.1[235.6,298.2]$ & .73 \\
\hline Depression & $.32[.28, .36]$ & $.17[.13, .21]$ & $243.4[229.3,256.3]$ & .97 & $.31[.26, .35]$ & $.11[.08, .15]$ & $232.0[209.2,252.0]$ & .76 \\
\hline Emotional Volatility & $.27[.22, .31]$ & $.08[.04, .12]$ & $311.8[280.5,348.9]$ & .69 & $.24[.19, .29]$ & $.02[.01, .07]$ & $64.8[281.0,210.0]$ & .13 \\
\hline \multicolumn{9}{|l|}{ Openness Facets } \\
\hline Aesthetic Sensitivity & $.00[-.05, .05]$ & $.07[.03, .12]$ & $267.4[221.9,304.7]$ & .61 & $.01[-.04, .06]$ & $.06[.02, .12]$ & $289.3[238.7,337.0]$ & .56 \\
\hline Intellectual Curiosity & $-.01[-.07, .04]$ & $.05[.02, .10]$ & $101.7[44.9,161.5]$ & .38 & $-.01[-.06, .05]$ & $.04[.01, .09]$ & $69.6[338.5,126.4]$ & .50 \\
\hline Creative Imagination & $-.09[-.14,-.04]$ & $.09[.04, .15]$ & $82.9[50.7,111.6]$ & .77 & $-.10[-.15,-.04]$ & $.08[.03, .12]$ & $85.9[46.8,117.6]$ & .96 \\
\hline
\end{tabular}

Note. $N$ ranges from 683 to 691 . Elevation = average correlation, or mean level of interpersonal distress; Amplitude $=$ difference between the average and highest correlation, or interpersonal differentiation; Angle = angular location of interpersonal profile peak, or interpersonal problem style; $R^{2}=$ goodness-of-fit to a cosine curve, or interpersonal prototypicality. 
Table 8

CSIP and IIP-C Structural Summary Parameters for PID-5-FSF Scales

\begin{tabular}{|c|c|c|c|c|c|c|c|c|}
\hline \multirow[b]{2}{*}{ PID-5-FSF } & \multicolumn{4}{|c|}{ CSIP } & \multicolumn{4}{|c|}{ IIP-C } \\
\hline & Elevation $[\mathrm{CI}]$ & Amplitude [CI] & Angle $[\mathrm{CI}]$ & $R^{2}$ & Elevation $[\mathrm{CI}]$ & Amplitude [CI] & Angle [CI] & $R^{2}$ \\
\hline Negative Affect & $.35[.30, .40]$ & $.13[.09, .17]$ & $295.8[277.5,314.9]$ & .92 & $.35[.30, .39]$ & $.06[.02, .10]$ & $329.0[290.4,20.2]$ & .40 \\
\hline Detachment & $.31[.26, .35]$ & $.23[.19, .27]$ & $195.5[184.9,206.3]$ & .93 & $.34[.30, .39]$ & $.21[.17, .25]$ & $187.6[175.5,199.6]$ & .88 \\
\hline Disinhibition & $.27[.22, .31]$ & $.03[.01, .08]$ & $52.1[297.4,157.0]$ & .19 & $.27[.22, .32]$ & $.06[.03, .11]$ & $85.8[33.4,125.9]$ & .71 \\
\hline Psychoticism & $.24[.19, .28]$ & $.11[.07, .16]$ & $136.1[114.8,157.8]$ & .92 & $.26[.21, .31]$ & $.13[.08, .18]$ & $131.0[114.3,149.3]$ & .98 \\
\hline \multicolumn{9}{|l|}{ Negative Affect Facets } \\
\hline \multicolumn{9}{|l|}{ Detachment Facets } \\
\hline Withdrawal & $.30[.25, .35]$ & $.23[.19, .27]$ & $181.9[171.2,193.8]$ & .97 & $.31[.27, .36]$ & $.21[.18, .25]$ & $178.7[166.8,191.1]$ & .91 \\
\hline Anhedonia & $.31[.26, .36]$ & $.18[.13, .22]$ & $202.2[186.6,216.9]$ & .95 & $.32[.27, .37]$ & $.14[.11, .18]$ & $184.1[166.6,202.1]$ & .95 \\
\hline Intimacy Avoidance & $.11[.06, .16]$ & $.15[.11, .19]$ & $202.4[184.5,220.2]$ & .75 & $.17[.13, .21]$ & $.15[.11, .18]$ & $199.8[181.4,218.5]$ & .66 \\
\hline \multicolumn{9}{|l|}{ Antagonism Facets } \\
\hline Manipulativeness & $.16[.11, .22]$ & $.25[.21, .30]$ & $98.1[86.7,108.7]$ & .94 & $.18[.12, .23]$ & $.28[.24, .33]$ & $109.3[100.6,117.5]$ & .97 \\
\hline Distractibility & $.24[.19, .29]$ & $.09[.05, .14]$ & $284.9[257.5,312.9]$ & .77 & $.24[.19, .29]$ & $.05[.02, .10]$ & $295.6[234.8,351.3]$ & .57 \\
\hline \multicolumn{9}{|l|}{ Psychoticism Facets } \\
\hline Unusual Experiences & $.13[.08, .19]$ & $.10[.06, .15]$ & $103.0[76.8,126.5]$ & .96 & $.15[.10, .20]$ & $.12[.08, .17]$ & $113.5[93.2,132.8]$ & .94 \\
\hline Eccentricity & $.24[.19, .28]$ & $.12[.08, .17]$ & $146.0[126.9,166.6]$ & .90 & $.25[.20, .30]$ & $.10[.06, .15]$ & $137.5[116,163.6]$ & .85 \\
\hline Perc. Dysregulation & $.20[.14, .26]$ & $.07[.03, .12]$ & $159.7[114.0,205.1]$ & .77 & $.23[.17, .28]$ & $.10[.06, .15]$ & $144.9[119.9,176.0]$ & .87 \\
\hline
\end{tabular}

Note. $N$ ranges from 676 to 687. Elevation = average correlation, or mean level of interpersonal distress; Amplitude $=$ difference between the average and highest correlation, or interpersonal differentiation; Angle = angular location of interpersonal profile peak, or interpersonal problem style; $R^{2}=$ goodness-of-fit to a cosine curve, or interpersonal prototypicality. 
Table 9

Variance Explained by the CSIP and IIP-C on BFI-2 Trait Domains, PID-5-FSF Maladaptive Traits, and BSI-18 Syndromes

\begin{tabular}{|c|c|c|c|c|}
\hline Outcome & $\begin{array}{l}\text { Total \% of Variance } \\
\text { Explained by the CSIP } \\
\text { and IIP-C }\end{array}$ & $\begin{array}{l}\% \text { of Unique Variance } \\
\text { Explained by the CSIP }\end{array}$ & $\begin{array}{l}\% \text { of Unique Variance } \\
\text { Explained by the IIP-C }\end{array}$ & $\%$ of Shared Variance \\
\hline \multicolumn{5}{|l|}{ BFI-2 } \\
\hline Extraversion & 59.86 & 8.62 & 1.43 & 49.81 \\
\hline Agreeableness & 52.39 & 3.88 & 13.5 & 35.01 \\
\hline Conscientiousness & 16.15 & 3.60 & 3.35 & 9.20 \\
\hline Neuroticism & 31.71 & 8.61 & 3.41 & 19.69 \\
\hline Openness to Experience & 7.66 & 4.65 & 2.07 & 0.94 \\
\hline \multicolumn{5}{|l|}{ PID-5-FSF } \\
\hline Negative Affect & 36.27 & 6.41 & 3.94 & 10.35 \\
\hline Detachment & 47.36 & 3.16 & 7.35 & 36.85 \\
\hline Antagonism & 39.97 & 3.87 & 9.43 & 26.67 \\
\hline Disinhibition & 22.22 & 3.91 & 3.18 & 15.13 \\
\hline Psychoticism & 21.28 & 2.99 & 3.29 & 15.00 \\
\hline \multicolumn{5}{|l|}{ BSI-18 } \\
\hline Depression & 32.43 & 5.01 & 2.15 & 25.27 \\
\hline Anxiety & 24.25 & 2.87 & 2.62 & 18.76 \\
\hline Somatization & 16.57 & 2.34 & 1.40 & 12.83 \\
\hline
\end{tabular}

Note. $N$ ranges from 675 to 685 . 
Figure 1

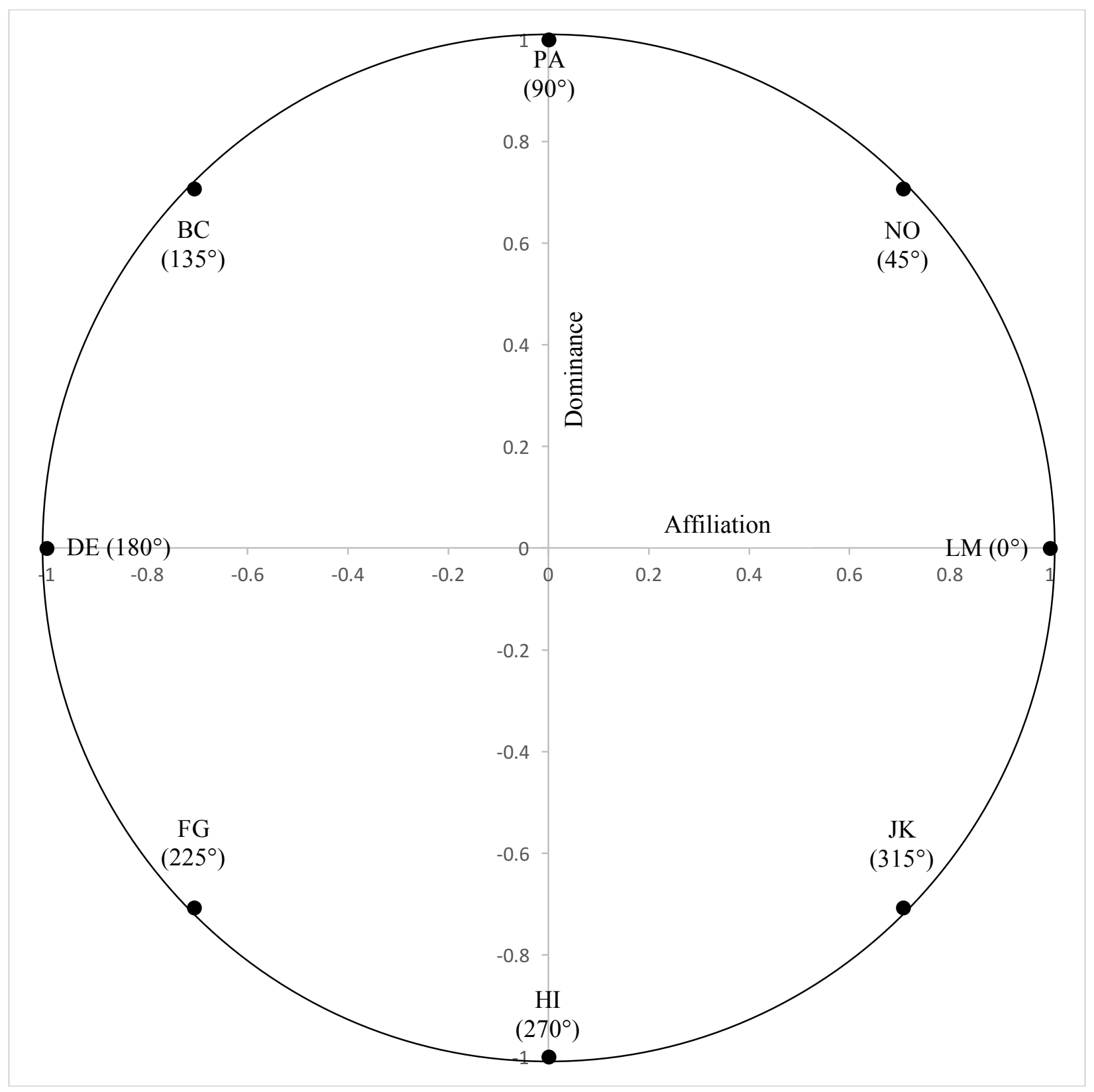

Theoretical circumplex structure of interpersonal problems.

Note. $\mathrm{PA}=$ Domineering; $\mathrm{BC}=$ Selfish $/$ Vindictive $\mathrm{DE}=$ Distant $/$ Cold $; \mathrm{FG}=$ Socially Inhibited $\mathrm{HI}=$ Nonassertive; $\mathrm{JK}=$ Exploitable/Overly Accommodating; $\mathrm{LM}=$ Self-Sacrificing; $\mathrm{NO}=$ Intrusive. 
Figure 2

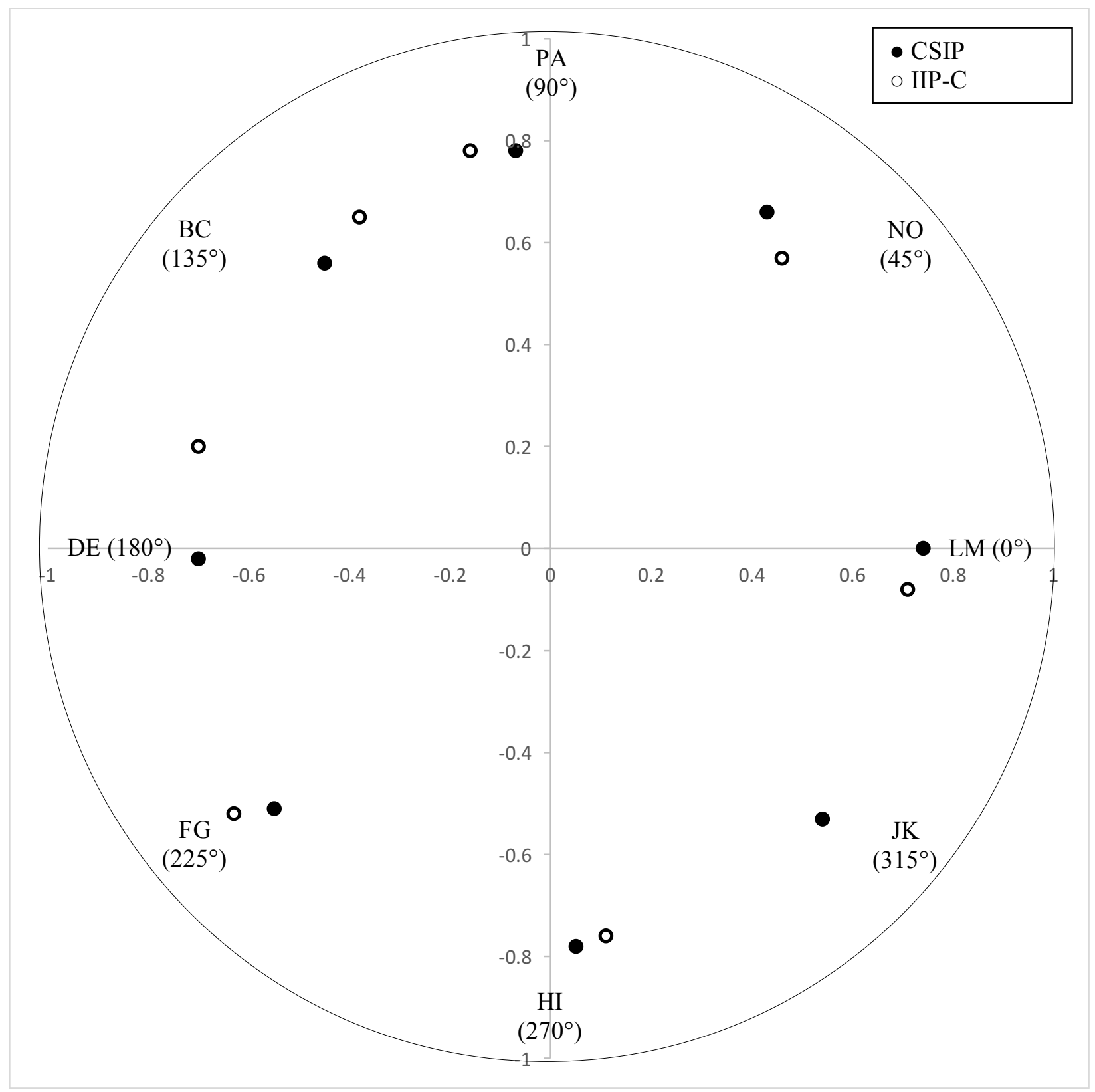

Structure of CSIP and IIP-C circumplex scales. Solution rotated for maximum convergence to theoretical angular locations.

Note. $\mathrm{PA}=$ Domineering; $\mathrm{BC}=$ Self-Centered/Vindictive; $\mathrm{DE}=$ Distant $/ \mathrm{Cold} ; \mathrm{FG}=$ Socially Inhibited; HI $=$ Nonassertive; JK = Exploitable/Overly Accommodating; $\mathrm{LM}=$ Self-Sacrificing; $\mathrm{NO}=$ Intrusive. As shown in Table 5 , the JK scales of the CSIP and IIP-C had the same location, and are displayed here with a single mark. 